\title{
Penerapan Pencahayaan Buatan Terhadap Karya di Ruang Galeri Foto pada Perancangan Interior Pusat Fotografi di Bandung
}

\author{
Dhia Fakhirah', Mahendra Nur Hadiansyah ${ }^{2}$, Ganesha Puspa Nabila ${ }^{3}$ \\ 1,2,3Program Studi Desain Interior, Fakultas Industri Kreatif, Universitas Telkom Bandung \\ dhiafakhirah@student.telkomuniversity.ac.id ${ }^{1}$, mahendrainterior@ telkomuniversity.ac.id ${ }^{2}$, \\ ganeshabella@telkomuniversity.ac.id ${ }^{3}$
}

\begin{abstract}
ABSTRAK
Galeri merupakan ruangan yang digunakan untuk mempamerkan karya seni. Galeri dapat dijadikan sebagai tempat untuk kegiatan rekreasi, hiburan, edukasi, bisnis, serta apresiasi kepada seniman. Galeri foto merupakan ruangan yang mempamerkan karya-karya fotografi dari para fotografer. Dalam ruang galeri, peran pencahayaan buatan terhadap karya yang di pamerkan cukup penting. Dengan pencahayaan buatan dapat menonjolkan serta memfokuskan para pengunjung ke karya. Dengan pengaturan pencahayaan buatan, juga dapat menimbulkan kesan-kesan tertentu terhadap karya. Penggunaan pencahayaan buatan lebih baik dibandingkan pencahayaan alami, dimana pencahayaan alami lebih rentan dapat merusak karya dari sinar ultraviolet. Pada studi kasus perancangan pusat fotografi ini, pengaplikasian pencahayaan pada ruang galeri dapat memberikan kesan-kesan tertentu terhadap karya, dengan pengaturan dari arah cahaya, jenis, dan teknik yang digunakan pada ruangan.
\end{abstract}

Kata kunci: pencahayaan; galeri foto; pusat fotografi

\section{ABSTRACT}

The gallery is a room used to display art. The gallery can be used as a place for recreation, entertainment, education, business, and appreciation for artists. The photo gallery is a room that shows artworks by photographers. In the gallery space, the role of artificial lighting in photos is quite important. Artificial lighting can highlight and focus the visitors to the artworks. it settings can also make impressions on the work. The use of artificial lighting is better than natural lighting, where natural lighting is more vulnerable to damage the photos because ultraviolet light. In this case, the application of lighting in the gallery space can give certain impressions to the work, with the setting of the light direction, type, technique, and the amount of lumens used in the room to comply with the standards.

Keyword: lighting; photo gallery; photography center

\section{PENDAHULUAN}

Perkembangan dunia fotografi di Indonesia di mulai sejak tahun 2000-an, di mana dengan dimulainya kamera menggunakan sensor digital. Di Indonesia pada saat ini, dunia fotografi mengalami peningkatan, bahkan terjadi cukup signifikan. Peningkatan tersebut dapat di lihat dari munculnya komunitas fotografi tertua dan pertama di Indonesia yang berada di Bandung, komunitas tersebut bernama Perhimpunan Amatir Foto Bandung (PAF). Seiring berkembangnya waktu, komunitas fotografi yang ada di Bandung semakin meningkat, hingga saat ini terbukti dengan adanya 10 komunitas dengan jumlah keseluruhan terdapat 1 juta pengikut media sosial dan 7 ribu anggota offline.

Dalam dunia fotografi, tidak lepas para fotografer terus belajar dari setiap pengalaman pribadi maupun pengalaman fotografer lainnya. Pengalaman tersebut didapatkan pada saat pelaksanaan salah satu acara rutin yaitu kegiatan pameran, baik yang berbasis nasional maupun internasional yang dilakukan di ruang galeri foto. Pelaksanaan di ruang galeri foto dapat dijadikan sebagai ajang edukasi, rekreasi, hiburan, bisnis, serta apresiasi kepada seniman. Dengan adanya galeri foto, diharapkan karya para fotografer dapat dinikmati dan dikenal oleh masyarakat. 
Pada ruang galeri, salah satu faktor yang memiliki peran penting adalah cahaya. Dengan cahaya, dapat memberikan penglihatan yang jelas terhadap karya serta informasi mengenai karya. Pencahayaan juga dapat memberikan kesan dan efek-efek tertentu tergantung dari pengaturan arah, jenis, dan teknik penggunaannya. Penggunaan cahaya terhadap karya juga harus sesuai dengan standar agar tidak merusak karya. Maka dari itu, penting adanya pengaturan pencahayaan buatan terhadap karya pada ruang galeri di perancangan pusat fotografi ini, guna pelaksanaan kegiatan di ruang galeri dapat berjalan dengan baik dan lancar.

\section{METODE PENELITIAN}

Menggunakan metode penelitian dengan melakukan analisa ke beberapa galeri secara langsung untuk melihat penggunaan pencahayaan buatan terhadap karya, seperti Selasar Sunaryo Art Space, galeri PAF Bandung, dan Museum Barli, guna dijadikan sebagai pembanding dan acuan untuk kegiatan pameran di ruang galeri pada perancangan interior pusat fotografi.

\section{A. Metode Pengumpulan Data}

Menggunakan metode penelitian dengan mengumpulkan data-data hasil survey observasi secara langsung ke ketiga studi bading yang ada di Indonesia serta melakukan dokumentasi gambar. Pelaksanaan kegiatan tersebut dilakukan guna sebagai tolak ukur, pembanding, dan contoh yang akan diterapkan ke dalam projek perancangan. Selain survey studi banding, juga melakukan pencarian referensi data mengenai galeri.

\section{B. Analisa Data}

Data survey observasi secara langsung ke lokasi studi banding akan di analisa dengan tabel komparasi guna dapat membandingkan dengan mudah dan mendapatkan kesimpulan mengenai peran cahaya buatan terhadap karya di galeri foto. Selain analisa hasil survey, referensi yang didapatkan akan dijadikan juga sebagai data pendukung.

\section{HASIL PENELITIAN DAN PEMBAHASAN}

\section{A. Standarisasi Tata Cahaya di Ruang Galeri}

Pengertian pusat merupakan suatu tempat yang di peruntukkan melakukan segala hal kegiatan yang dibutuhkan. Pusat berartikan juga inti dari segala aktivitas dan kegiatan yang dimana dapat memenuh kebutuhan para pengguna. Pengertian pusat fotografi adalah suatu tempat yang melayani dan menfasilitasi berbagai bentuk kegiatan fotografi baik yang bersifat edukasi, rekreasi, hiburan, bisnis, dan berbagai hal lainnya yang dapat memenuhi kebutuhan para komunitas. Galeri merupakan ruangan atau gedung yang digunakan sebagai tempat mempamerkan benda atau karya seni dan sebagainya. Galeri foto ditunjukkan untuk memamerkan hasil karya fotografer, dimana dapat dijadikan sebagai objek pembelajaran, reksreasi, diskusi, bahkan pelelangan.

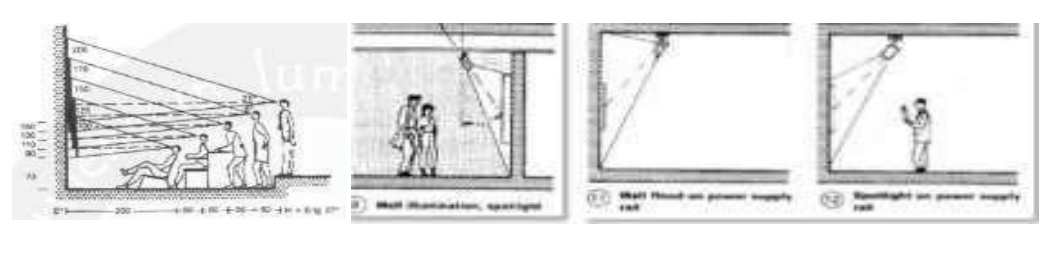

Gambar 1. Standar Penerangan Galeri

Sumber: Neufert, Ernst dan Peter, Architect Data, Third Edition (2000) 
Vol. 5, No. 2, Desember 2020, pISSN 2527-2853, eISSN 2549-2985

Tabel 1. Tabel Kebutuhan Iluminasi Berdasarkan Aktivitas

\begin{tabular}{|r|l|c|}
\hline No. & \multicolumn{1}{|c|}{ Kerja visual } & Iluniminasi (lux) \\
\hline 1 & Penglihatan keadaan normal/biasa & 100 \\
\hline 2 & Kerja berat/kasar dengan detail objek besar & 200 \\
\hline 3 & Kerja umum dengan detail wajar & 400 \\
\hline 4 & $\begin{array}{l}\text { Kerja dengan ukuran penglihatan detail kecil } \\
\text { (studio, } \\
\text { gambar, menjahit) }\end{array}$ & 600 \\
\hline 5 & $\begin{array}{l}\text { Kerja berat, dalam waktu lama, dengan detail } \\
\text { ukuran } \\
\text { kecil (barang halus, menjahit dengan tangan) }\end{array}$ & 900 \\
\hline 6 & $\begin{array}{l}\text { Kerja keras dalam waktu yang sangat lama } \\
\text { dengan detail objek sangat kecil } \\
\text { (pemotongan batu mulia, } \\
\text { mengukur benda sangat kecil) }\end{array}$ & $1300-2000$ \\
\hline
\end{tabular}

Sumber: Dr. Yeffry Handoko Putra, S.T, M.T. Standar Pencahayaan (2009)

Berdasarkan tabel kebutuhan di atas, pada ruang galeri foto akan menggunakan standar lux pencahayaan buatan dengan besaran 400. Standar tersebut digunakan agar penerangan terhadap karya dapat terlihat dengan detail dan jelas, serta penerangan yang sesuai standar akan menjaga kualitas karya yang di pamerkan.

Dalam buku lesna (2000:127), terdapat beberapa faktor yang harus di hindarkan guna mendapatkan kenyaman dalam penglihatan pada bidang kerja, diantaranya:

1. Silau (Glare)

Terdapat dua silau, yaitu disability glare, merupakan silau yang mengakibatkan mata tidak dapat melihat akibat pancaran cahaya dalam jumlah besar yang menuju ke arah mata. Sedangkan discomfort glare merupakan silau yang mucul akibat pantulan cahaya ke arah suatu bidang kerja yang menuju ke mata.

2. Bayangan (Shadow)

Sinar cahaya yang jatuh ke suatu bidang, kemudian terhalangi oleh suatu objek, sehingga menghasilkan bayangan objek dengan warna yang hitam.

3. Cahaya Kejut (Flicker)

Ketidak konseistenan cahaya yang dihasilkan oleh sumber cahaya, sehingga mengakibatkan berubahnya intensitas cahaya degan cepat.

Menurut Muman \& Hadiansyah (2016), mengenai jarak dan sudut pandang penglihatan terbagi secara vertikal dan horizontal. Standar untuk pengukuran sudut pandang penglihatan secara horizontal adalah $45^{\circ}+45^{\circ}$ dan standar pengukuran sudut pandang secara vertikal adalah $30^{\circ}$ (University of Maryland, 2000), (Ahlstrom, 2007).

Menurut Carena \& Wulandari (2016), untuk mencapai efektifitas dan efisiensi dalam penggunaan cahaya buatan di dalam ruang, cahaya buatan mempunyai jenis dan sistem penerangannya sendiri, diantaranya:

\section{Sistem Lighting Primer}


a. General Lighting (Down Light), dengan penerangan merata.

b. Localized Lighting (Free Standing Ip Lighter), dengan tata cahaya khusus untuk menerangi suatu area.

c. General Lighting dan Localized Lighting, membutuhkan intensitas tertentu pada lux cahaya.

2. Sistem Lighting Sekunder

a. Task Light, menyoroti suatu area kerja atau cahayanya bertujuan yang fungsional.

b. Accent Light, sebagai sinar aksen atau estetika.

c. Ambient Light, penerangan secara merata.

d. Decorative Light, sebagai cahaya dekor interior yang menggunakan intensitas dan warna cahaya tertentu guna membangun suasana ruang.

e. Effect Light, objek dan cahaya sebagai fokus utama atau pusat perhatian.

f. Architecture Light, media pendukung dari cahaya.

Dalam pencahayaan buatan, terdapat beberapa teknik pengaturan, diantaranya:

1. Wall Wash, pencahayaan yang menyoroti dinding agar memiliki kesan rata dengan cahaya.

2. High Lighting, cahaya yang menyoroti dengan tujuan memfokuskan ataupun memperjelas detail karya.

3. Beam Play, elemen visual yang berasal dari cahaya sorot.

4. Silhouetting, pencahayaan yang menyoroti karya, namun dengan bentukan hasil karya seni dalam wujud bayangan.

5. Shadow Play, bayangan dari hasil cahaya sorot sebagai elemen visual.

6. Sparke, elemen visual yang berasal dari sumber cahaya.

Pada pencahayaan buatan, terdapat teknik berkas cahaya yang berasal dari beragam jenis armature lampu, diantaranya:

1. Indirect, pancaran cahaya $>90 \%$ ke atas dengan ceiling sebagai pemantul pada bidang yang memiliki reflektansi cukup besar.

2. Semi Indirect, pancaran cahaya $>60 \%$ ke atas dan $40 \%$ ke bawah.

3. Semi Direct, pancaran cahaya yang mengarah ke atas $50 \%$ dan kebawah $50 \%$.

4. Direct, pancaran cahaya. $90 \%$ ke arah bawah.

5. Diffused, pancaran cahaya yang merata.

\section{B. Perbandingan Kondisi Tata Cahaya Pada Beberapa Galeri di Bandung}

Adanya kegiatan dengan melakukan survey ke beberapa lokasi studi banding secara langsung guna menambahkan referensi data dan dapat dijadikan sebagai tolak ukur maupun pembanding.

Tabel 2. Tabel Kebutuhan Iluminasi Berdasarkan Aktivitas

\begin{tabular}{|c|c|c|}
\hline Galeri PAF Bandung & Selasar Sunaryo Art Space & Museum Barli \\
\hline \multicolumn{3}{|l|}{ Lokasi } \\
\hline $\begin{array}{l}\text { Komplek Banceuy Permai, } \\
\text { Kav. A/17, Braga, Kec. } \\
\text { Sumur Bandung, Kota } \\
\text { Bandung, Jawa Barat } 40111 .\end{array}$ & $\begin{array}{l}\text { Jl. Bukit Pakar Timur } \\
\text { No.100, Ciburial, Kec. } \\
\text { Cimenyan, Bandung, Jawa } \\
\text { Barat } 40198\end{array}$ & $\begin{array}{l}\text { J1. Prof. Dr. Sutami No.91, } \\
\text { Sukarasa, Kec. Sukasari, } \\
\text { Kota Bandung, Jawa Barat } \\
40152\end{array}$ \\
\hline
\end{tabular}




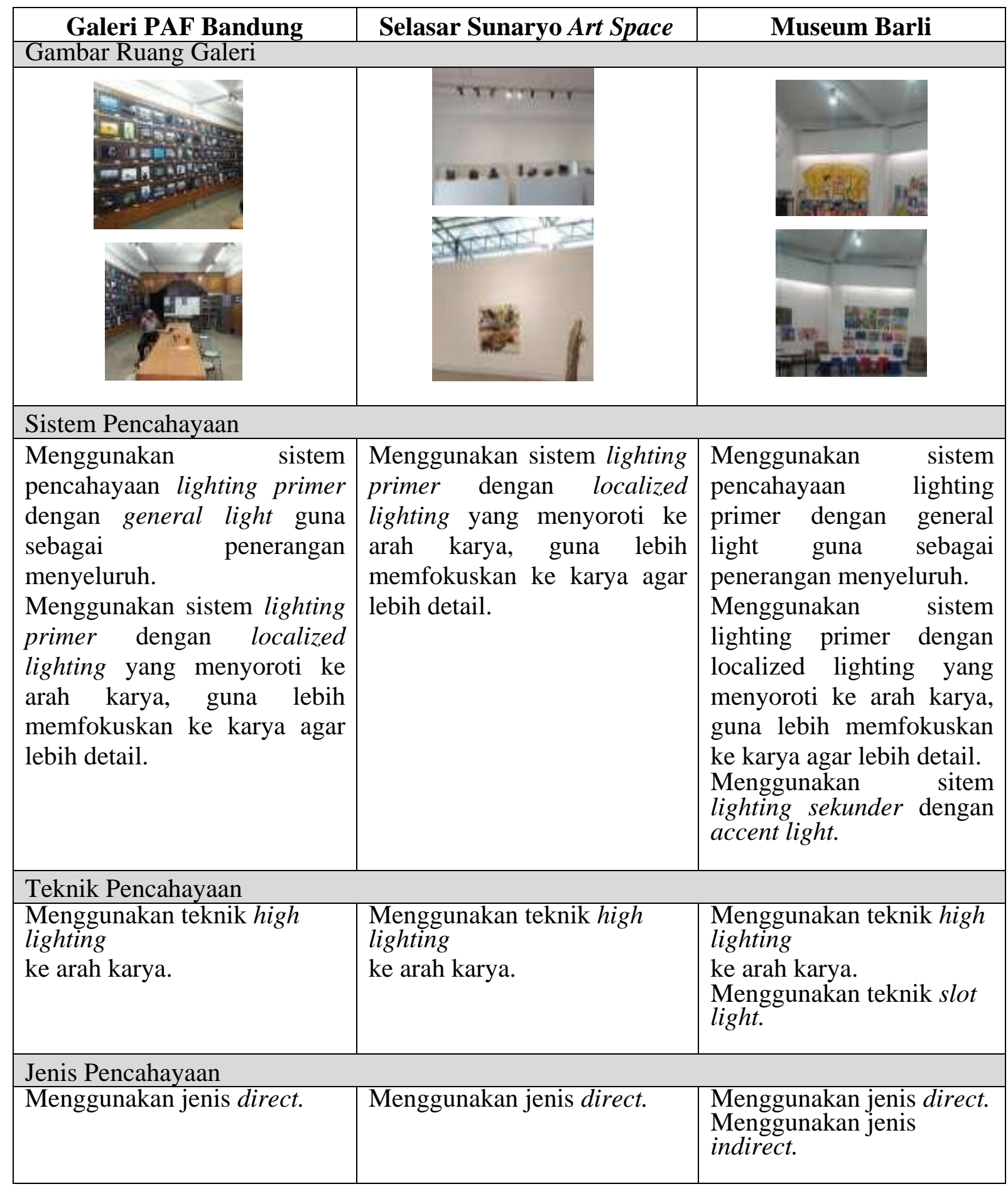

Sumber: Analisa Penulis (2020)

\section{Perancangan Tata Cahaya Pada Interior Galeri Pusat Fotografi di Bandung}




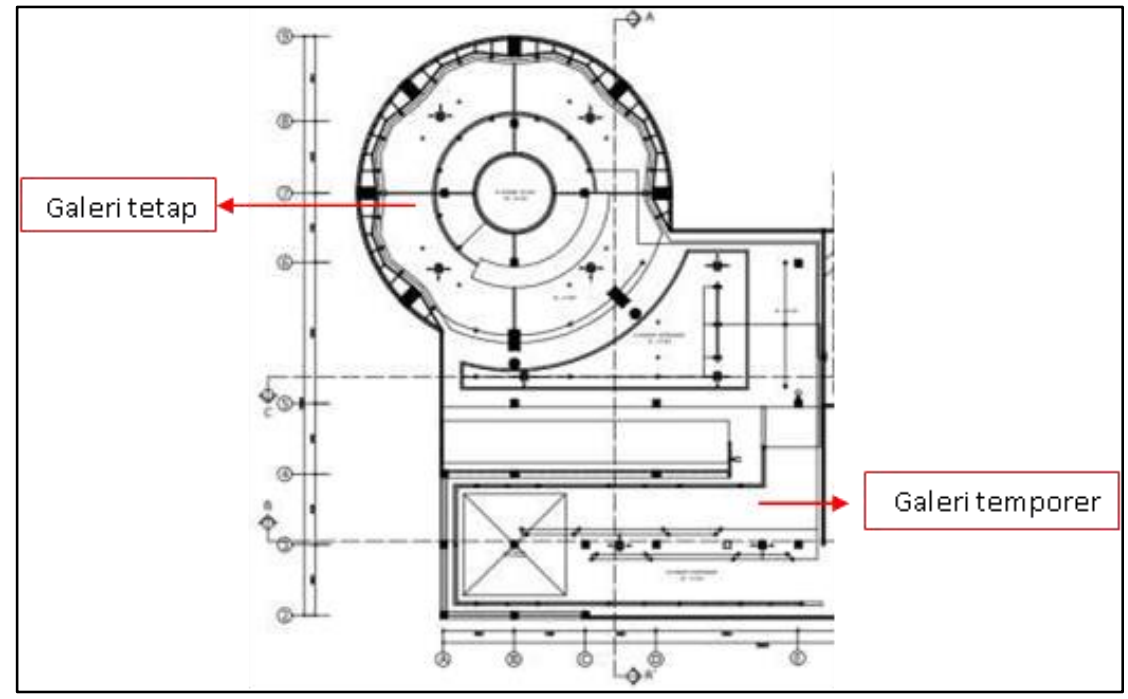

Gambar 2. Gambar Kerja Pola Ceiling Galeri Lt.1 Sumber: Data Penulis (2020)

Pada denah teknikal di atas, merupakan ruang galeri lt.1 yang terdapat jalur titik lampu dengan menggunakan rangkaian paralel. Area galeri temporer lantai 1 memiliki luasan $338 \mathrm{~m}^{2}$ sehingga membutuhkan lumen sebesar 101.400 dengan standar lux 300-400. Total lampu yang di gunakan 20 buah down lamp dengan 35w/lampu dan 59 buah spotlight dengan 9w/lampu. Menggunakan sistem lighting primer dengan general lighting guna menerangi area sirkulasi dan localized lighting yang memfokuskan ke karya. Terdapat juga penggunaan lampu sistem lighting sekunder dengan accent lighting. Teknik dalam pengaturan cahayanya sendiri menggunakan high lighting untuk memperjelas detail karya. Jenis armature yang digunakan lampu sorot dengan indirect lighting dan down lamp dengan direct lighting.

Pada ruang galeri tetap di lantai 1, memiliki luasan ruang $189 \mathrm{~m}^{2}$ sehingga membutuhkan lumen sebesar 50.700 dengan standar lux 300. Membutuhkan 3 buah lampu down lamp dengan $35 \mathrm{w} / \mathrm{lampu}, 57$ buah lampu spot dengan 9w/lampu, dan 4 buah lampu TL dengan 11w/lampu. Menggunakan sistem lighting primer dengan general lighting guna menerangi area sirkulasi dan localized lighting. Terdapat juga penggunaan lampu sistem lighting sekunder dengan accent lighting. Menggunakan teknik high lighting untuk memperjelas detail karya. Jenis armature yang digunakan lampu sorot dengan indirect lighting dan down lamp dengan direct lighting.
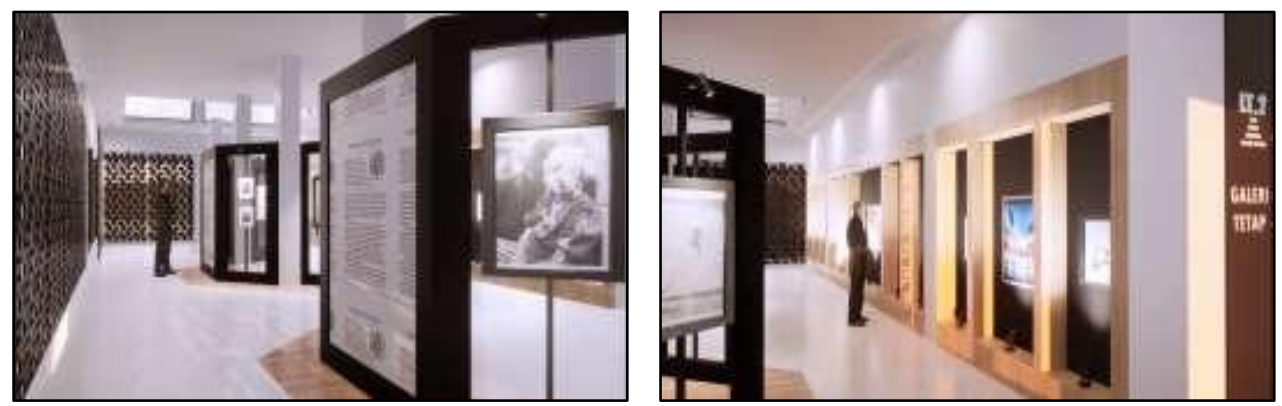

Gambar 3. Suasana Galeri Temporer Lt.1 Sumber: Data Penulis (2020) 
Pada gambar di atas, merupakan gambaran suasana ruang galeri temporer lantai 1. Menggunakan berbagai arah datang cahaya dengan berbagai jenis, teknik, dan sistem. Menggunakan warna cahaya warm untuk menonjolkan karya dan menambah kesan elegan. Lampu berwarna putih di area sirkulasi sebagai pencahayaan netral yang menyeluruh.
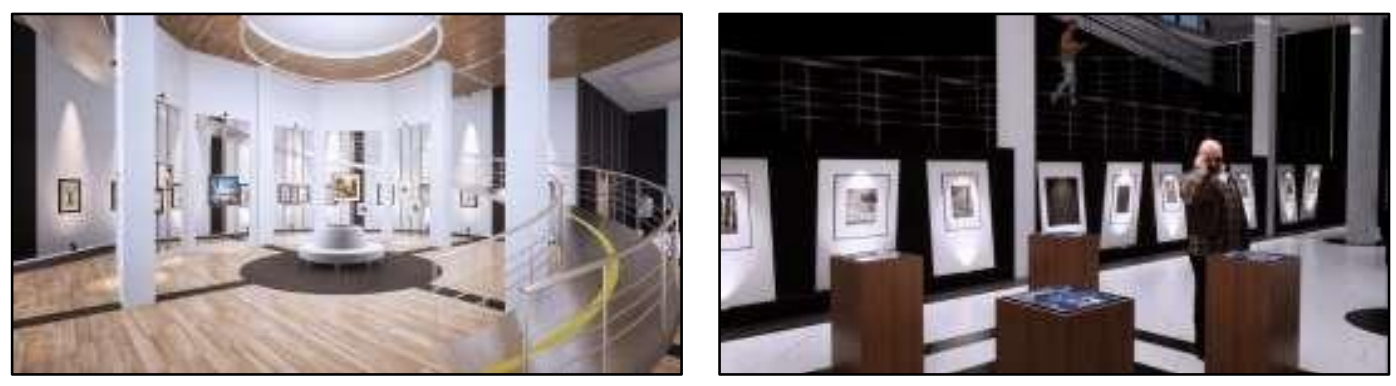

Gambar 4. Suasana Galeri Tetap Lt.1

Sumber: Data Penulis (2020)

Gambar di atas merupakan suasana ruang galeri tetap lantai 1. Menggunakan beragam arah datang cahaya baik dari atas maupun bawah dan menggunakan warna cahaya warm yang menyoroti karya guna menambah kesan dramatis dan elegan.

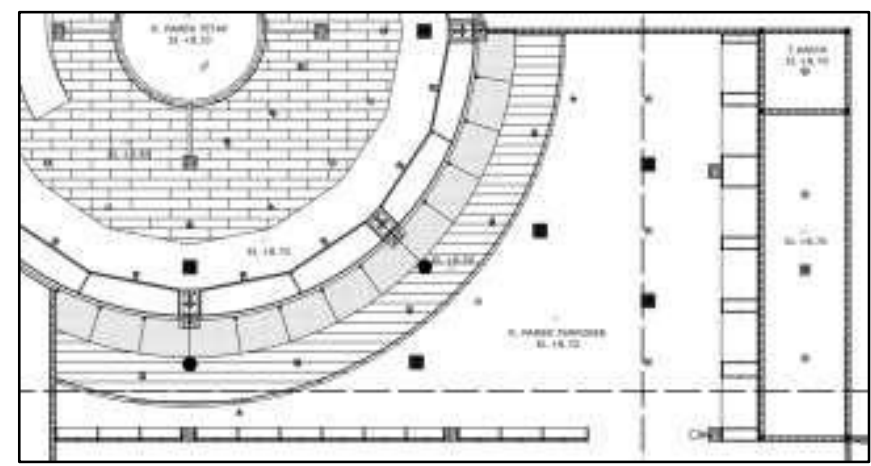

Gambar 5. Gambar Kerja Pola Ceiling Galeri Lt.2 Sumber: Data Penulis (2020)

Pada gambar denah teknikal di atas, merupakan perencanaan titik lampu galeri temporer lantai 2 dengan menggunakan rangkaian paralel. Area tersebut memiliki luasan $149 \mathrm{~m}^{2}$ sehingga membutuhkan lumen sebesar 44.700 dengan standar lux 300-400. Total lampu yang digunakan 8 buah down lamp dengan 35w/lampu, 6 buah lampu TL dengan 11w/lampu, dan 30 buah spotlight dengan $9 \mathrm{w} /$ lampu. Menggunakan sistem lighting primer dengan general lighting guna menerangi area sirkulasi dan localized lighting yang memfokuskan ke karya. Terdapat penggunaan lampu sistem lighting sekunder dengan effect lighting. Teknik dalam pengaturan cahaya menggunakan high lighting untuk memperjelas detail karya dan slot light pada ceiling dengan indirect lamp. Jenis armature yang digunakan lampu sorot dengan indirect lighting dan down lamp dengan direct lighting. 


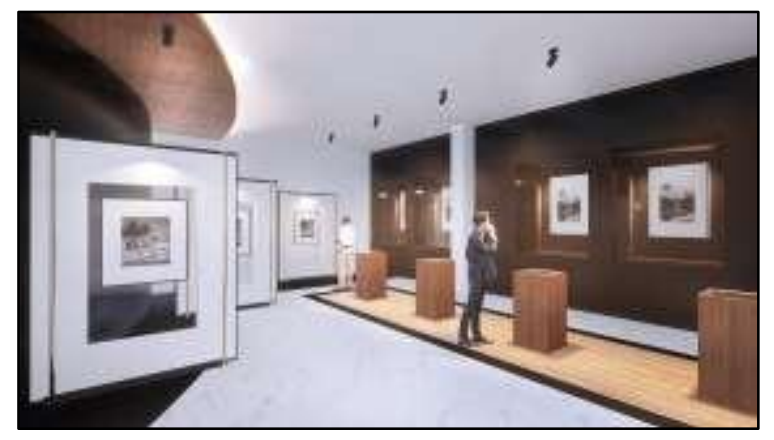

Gambar 6. Suasana Galeri Temporer Lt.2 Sumber: Data Penulis (2020)

Pada gambar di atas merupakan gambaran suasana ruang galeri temporer lantai 2. Menggunakan beragam arah datang cahaya baik dari atas, belakang, maupun samping dan menggunakan warna cahaya warm yang menyoroti karya guna menambah kesan dramatis dan elegan.

\section{KESIMPULAN}

Berdasarkan hasil data analisa studi banding dan referensi mengenai pencahayaan buatan di galeri dapat di simpulkan bahwa pada perancangan pusat fotografi di Bandung menggunakan pencahayaan buatan berdasarkan perhitungan lumen dari luasan peruang dan lux yang sesuai dengan standar 400-300. Kemudian sistem cahaya dominan menggunakan lighting primer dengan general lighting dan localized lighting. Teknik dalam pengaturan cahaya dominan menggunakan high lighting dan slot light pada ceiling dengan indirect lamp. Jenis armature yang digunakan dominan lampu sorot dengan indirect lighting dan down lamp dengan direct lighting. Total jumlah lampu down lamp yang digunakan 31 buah dengan 35w/lampu, total lampu spot light 146 buah dengan 9w/lampu, dan total lampu TL 6 buah dengan 11w/lampu. Menggunakan pencahayaan dominan berwarna warm terhadap karya dan putih terhadap penerangan ke sirkulasi ruang. Dengan beragam sistem, teknik, dan jenis yang digunakan pada pencahayaan buatan di ruang galeri, dapat menonjolkan, memperjelas detail, serta memberikan kesan yang dramatis terhadap karya. Serta dengan adanya perhitungan besaran jumlah cahaya yang digunakan berdasarkan standar, dapat tidak merusak karya.

\section{DAFTAR PUSTAKA}

Carena, Sesilia Windy \& Wulandari, Ratri. (2016). Efek Pencahayaan Buatan Terhadap Tampilan Karya Di Roemah Seni Sarasvati. Vol.1 No.2 Edisi Agustus.

Mirzah, Amythia Lapadca, Gunawan, Ahmad Nur Sheha, Salayanti, Santi. (2017). Penerapan Pencahayaan Buatan pada Interior Restoran Atmosphere Bandung di Malam Hari. Vol.2 No.1 Edisi April

Muman, D. K \& Hadiansyah, N. M. (2016). Analisis Jarak dan Sudut Pandang Posisi Duduk pada Ruang Perkuliahan Terhadap Efektivitas Belajar Mahasiswa di Gedung Tokong Nanas Universitas Telkom. Jurnal Idealog Vol.1, No.2.

Neufert, Ernst, (1996), Data Arsitek Jilid 1 Edisi 33. Jakarta: Erlangga. Neufert, Ernst, (2002), Data Arsitek Jilid 2 Edisi 33. Jakarta: Erlangga.

Putra, Yeffry Handoko. (2009). Standar Pencahayaan.

Rea, Mark Stanley. (2000). The IESNA Lighting Handbook. New York: Illuminating Engineering Society. 